\title{
Inheritance of the amplified esterase genes responsible for insecticide resistance in Myzus persicae (Homoptera: Aphididae)
}

\author{
R. L. BLACKMAN*†, J. M. SPENCE†, L. M. FIELD $\ddagger, N$. JAVED $\ddagger$, G. J. DEVINE $\ddagger$ \\ \& A. L. DEVONSHIRE $\ddagger$ \\ $\dagger$ Department of Entomology, The Natural History Museum, London SW7 5BD and $\ddagger$ Biological and Ecological \\ Chemistry Department, IACR-Rothamsted, Harpenden, Herts AL5 2JO, U.K.
}

\begin{abstract}
Insecticide-resistant and susceptible clones of Myzus persicae were induced to produce sexual morphs and crossed in the laboratory. Progeny clones were analysed for karyotype, esterase (E4, FE4 or S) gene type and activity, and amplified E4 and FE4 genes were located on their chromosomes by fluorescence in situ hybridization (FISH). Amplified FE4 genes of resistant parent clones ( $800 \mathrm{~F}$ and French $\mathrm{R}$ ) were inherited according to expectations. Chromosomal locations of these genes (on autosomes 1 and 3 in $800 \mathrm{~F}$, and on 1 and 2 in French R) were confirmed by FISH analysis of progeny that had inherited an autosome 2 marker (a dissociation) from the susceptible parent (DS). Inheritance of amplified $E 4$ genes could not be studied directly as none of the available clones was able to produce mating females. Males from two clones with amplified E4 genes (and with the A1,3 translocation that is common to all E4-producing genotypes) were therefore mated with females from clones with amplified $F E 4$ genes at known chromosomal locations. Progeny were obtained with both $E 4$ and FE4 genes, a combination not yet found in nature. Analysis of $F_{1}$ and subsequent generations confirmed that the amplified $E 4$ site on autosome $3^{T}$ is close to the translocation breakpoint, and apparently coallelic with the amplified FE4 site on the normal autosome 3 inherited from $800 \mathrm{~F}$. One of the translocated parent clones (4156) had two additional E4 sites, unlinked to the translocation, which were inherited according to expectation. Esterase activities of progeny clones, measured by immunoassay, mostly corresponded to the number of amplified sites inherited, with some discrepancies which could be attributed to copy number differences between sites, inheritance of partially methylated genes from French R, or position effect variegation at the site on $3^{\mathrm{T}}$. Inheritance of the A1,3 translocation in two crosses differed markedly from expectation.
\end{abstract}

Keywords: esterase genes, FISH, gene amplification, immunoassay, insecticide resistance, position effect.

\section{Introduction}

Throughout the world, populations of the peachpotato aphid Myzus persicae have developed resistance to a wide range of insecticides. The resistance arises from gene amplification, resulting in the increased production of esterases which hydrolyse and sequester insecticides before they reach their target sites (Devonshire \& Field, 1991). Two slightly different esterases are involved: $\mathrm{E} 4$, which is always found in aphids with an A1,3 chromosomal translocation, and FE4, an enzyme with a slightly higher

\footnotetext{
${ }^{*}$ Correspondence.
}

molecular weight which has only been found in aphids of apparently normal karyotype (Field et al., 1988, 1993).

Amplified FE4 genes, visualized by fluorescence in situ hybridization (FISH), occur on several chromosomes, whereas amplified $E 4$ sequences are almost always located at a single chromosomal site, on autosome $3^{\mathrm{T}}$ close to the translocation breakpoint; only one $M$. persicae clone has so far been found with amplified $E 4$ genes at other chromosomal locations (Blackman et al., 1995).

Myzus persicae reproduces mainly by apomictic parthenogenesis, but in temperate climates the succession of all-female viviparous generations may 
be interrupted by production of a single, annual bisexual generation. This happens in autumn, when males and mating, egg-laying females are produced in response to decreasing photoperiod and temperature. However, some genotypes do not respond to these environmental stimuli, or show only a partial response, so even in temperate climates only part of the population undergoes sexual reproduction. The partial response normally entails production of some males, but no mating females. Thus, although the conditions both for continuous parthenogenesis and for production of the bisexual generation can be mimicked using artificially controlled environments, not all genotypes can be induced to produce a bisexual generation for breeding purposes, and crossing experiments have to take this into account. Here we report on a series of such crosses between sexual morphs from resistant FE4-producing, resistant E4-producing and susceptible (low esterase) aphid clones, which were designed to investigate the relationships between karyotype, esterase type and activity, and the number of amplified loci and their chromosomal location. These crosses have enabled us to (1) confirm the location of the amplified sites on particular chromosomes, (2) compare the inheritance of E4-based and FE4-based resistance, (3) obtain clones with both $E 4$ and FE4 genes, which have not been found in nature, and (4) obtain clones with amplified genes at single sites, so that in future work we can study the particular properties of each site in isolation.

\section{Materials and methods}

\section{Aphid clones}

Aphid genotypes were reared and studied as clones. We will here refer to the clones from which sexual morphs were obtained for the initial crosses as the parental clones, and the genotypes produced in successive sexual generations as $F_{1}$ clones, $F_{2}$ clones, etc. The properties of the parental clones used in this study are listed in Table 1, and the lineages investigated in this paper are illustrated diagrammatically in Fig. 1.

None of the available insecticide-susceptible clones was able to produce any mating females, but one provided males in sufficient numbers for the initial crosses with mating females from two FE4-producing clones, French $\mathrm{R}$ and $800 \mathrm{~F}$. This susceptible clone (DS) was heterozygous for a dissociation of autosome 2, which provided a useful marker for this chromosome in half of its progeny (Fig. 1a).

The insecticide-resistant parental clones were characterized for number and chromosomal locations of amplified esterase genes using FISH (Blackman et al., 1995). Of the two FE4-producing clones, $800 \mathrm{~F}$ produces c. 70 times more esterase than susceptible aphids and has amplified genes at five sites, whereas French $\mathrm{R}$ has c. 15 times more esterase than susceptible aphids and three amplified sites. These two clones produced both males and mating females when subjected to reduced photoperiod and temperature (see below).

As with susceptible clones, no mating females were obtained from any of the available E4-producing, translocated clones. However, their later-born progeny in the second generation at $10 \mathrm{~h}$ photoperiod usually included a few males (see below), so studies of the inheritance of the $E 4$ genes were started by mating these with FE4-producing females from the $F_{1}$ of French $R \times D S$ and $800 F \times D S$ crosses (Fig. 1b,c). Two E4-producing parent clones were used, 4158 and 4156 . FISH showed that clone 4158 had all the amplified sequences at a single location on autosome $3^{\mathrm{T}}$, whereas clone 4156 had two other amplified sites unlinked to the translocation on autosomes 2 and 5 (Blackman et al., 1995).

Table 1 The origins, karyotypes and resistance properties of the parental clones of Myzus persicae

\begin{tabular}{llllccr}
\hline Clone & Origin & Karyotype & $\begin{array}{l}\text { Esterase } \\
\text { type }\end{array}$ & $\begin{array}{c}\text { No. of sites } \\
\text { with amplified } \\
\text { sequences* }\end{array}$ & $\begin{array}{c}\text { Resistance } \\
\text { level } \dagger\end{array}$ & $\begin{array}{c}\text { Esterase } \\
\text { activity } \\
\left(\mathrm{A}_{620} \pm \mathrm{SD}\right) \ddagger\end{array}$ \\
\hline DS & Germany, field & A2 dissociation & $\mathrm{S}$ & 0 & $\mathrm{~S}$ & $0.10( \pm 0.04)$ \\
4156 & U.K., field & A1,3 translocation & E4 & 3 & $\mathrm{R}_{2}$ & $1.13( \pm 0.29)$ \\
4158 & U.K., field & A1,3 translocation & E4 & 1 & $\mathrm{R}_{3}$ & $2.84( \pm 0.52)$ \\
French R & France, peach & Normal & FE4 & 3 & $\mathrm{R}_{2}$ & $1.57( \pm 0.78)$ \\
$800 \mathrm{~F}$ & Italy, peach & Normal & FE4 & 5 & $\mathrm{R}_{3}$ & $3.44( \pm 0.26)$ \\
\hline
\end{tabular}

*Blackman et al., 1995; †Field et al., 1988; łabsorbance at $620 \mathrm{~nm}$ determined by immunoassay, see Devonshire et al., 1986.

(C) The Genetical Society of Great Britain, Heredity, 77, 154-167. 
Although crosses between susceptible and E4-producing resistant genotypes were not possible initially, because neither produced mating females, the genes controlling life cycle category and those encoding

(a)
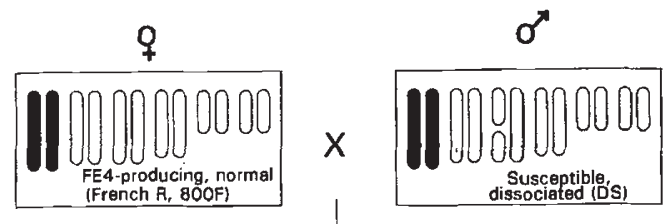

$F_{1}$

Parents
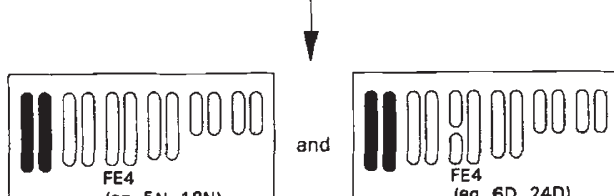
(eg. 6D, 24D)

$F_{2}$

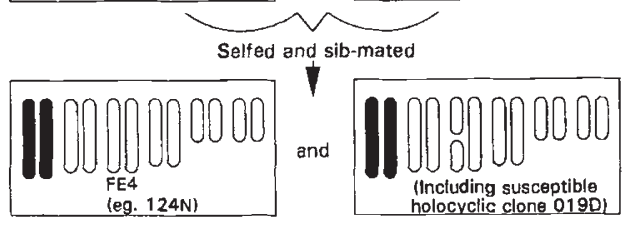

(b)
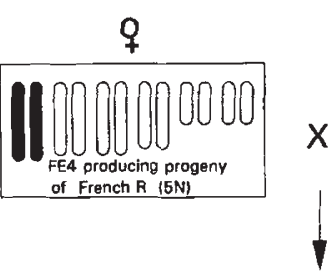

$F_{1}$
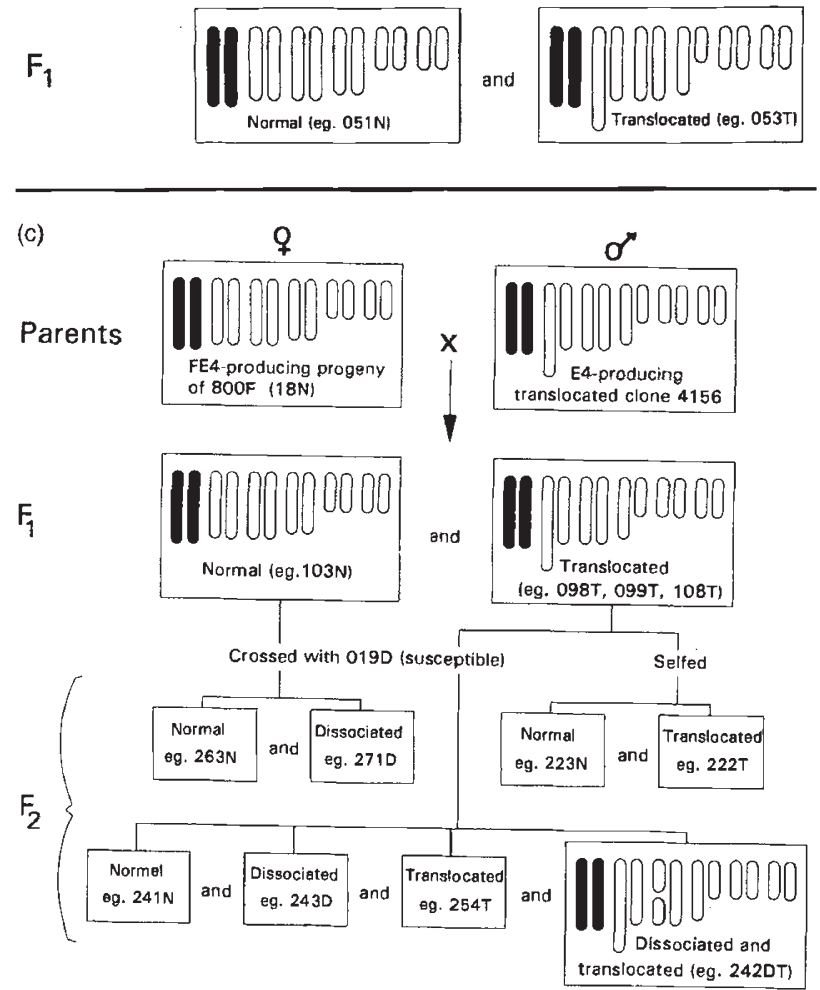

esterase proved to be unlinked. Consequently, the $\mathrm{F}_{2}$ generation from French $\mathrm{R} \times \mathrm{DS}$ provided one insecticide-susceptible clone (019D) that produced mating females, which could then be used in place of clone DS. Similarly, crosses between FE4-producing females and E4-producing males yielded some E4-producing, translocated clones able to produce mating females, so eventually the full range of options was available, and most of the possible combinations of karyotype, esterase type and amplified gene location could be realized.

\section{Breeding}

Myzus persicae clones maintained at $16 \mathrm{~h}$ photoperiod and $15^{\circ} \mathrm{C}$ reproduce by thelytokous (all-female), apomictic parthenogenesis. To induce the sexual phase, fourth instar parthenogenetic females were transferred to a $10 \mathrm{~h}$ photoperiod at $15^{\circ} \mathrm{C}$, and reared for two further parthenogenetic generations. In genotypes capable of a full response, the firstborn progeny of the second generation at $10 \mathrm{~h}$ are all winged parthenogenetic females (which under natural conditions would migrate to peach trees), and their progeny (that is, the third parthenogenetic generation at $10 \mathrm{~h}$ ) are mating, egg-laying females. Depending on genotype, the later-born progeny of the second generation at $10 \mathrm{~h}$ are either all males in the case of a full response, or a mixture of males and parthenogenetic females if the response is only partial. These two basic types of response, full and partial (or, in aphid life cycle terminology, holocyclic and androcyclic), are illustrated in Fig. 2.

All morphs were reared to adult on excised potato leaves in small, specially adapted polystyrene boxes (Blackman, 1988). Mature mating females were transferred to excised potato leaves in similarly

Fig. 1 (a) Scheme for crossing FE4-producing (French R, $800 \mathrm{~F})$ females $(2 n=12)$ with susceptible (DS) males of Myzus persicae, showing inheritance of autosome 2 dissociation and examples of normal and dissociated clones produced in the $F_{1}$ and $F_{2}$ sexual generations; (b) scheme for crossing females of clone $5 \mathrm{~N}$ (FE4-producing, normal karyotype) with males of clone 4158 (E4-producing, with A1,3 translocation), and examples of normal and translocated $F_{1}$ progeny clones; (c) scheme for crossing females of clone $18 \mathrm{~N}$ (FE4-producing, normal karyotype) with males of clone 4156 (E4-producing with A1,3 translocation), showing lineages described in text and giving examples of $F_{1}$ and $F_{2}$ progeny. Chromosomes are holocentric. X chromosomes are shown in black. Progeny with clone numbers ending in $\mathrm{N}, \mathrm{D}$ and $\mathrm{T}$ are, respectively, of normal, dissociated and translocated clones. 
Fig. 2 Production of males and mating females in Myzus persicae. Diagrams of the two common types of response to short photoperiod $(10 \mathrm{~h})$ at $15^{\circ} \mathrm{C}$.

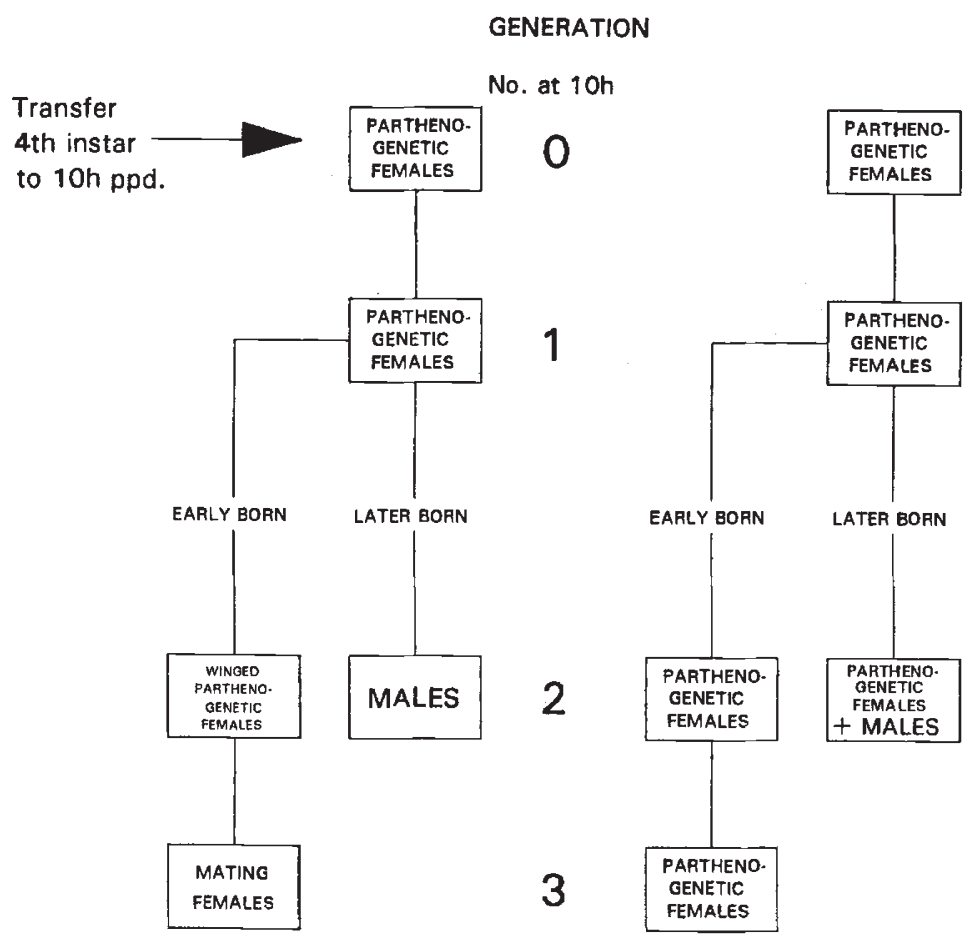

modified, but much larger, sandwich-type boxes $(17.5 \times 12 \times 6 \mathrm{~cm})$. Males were added in a ratio of approximately one to every two females, with 50-200 females per box. Mated females immediately started to lay eggs, partly on the leaves but mainly attached to the sides and lid of the box. When oviposition had finished, boxes with eggs were placed in an incubator with $12 \mathrm{~h}$ photoperiod and temperature cycling between $5^{\circ} \mathrm{C}$ (day) and $-2^{\circ} \mathrm{C}$ (night) for 65-70 days to complete diapause development. Boxes were then provided with fresh excised leaves and placed at a constant $15^{\circ} \mathrm{C}$. Hatching of any viable eggs started within 2 days. Hatchlings were reared to fourth instar and then separated into small rearing boxes at $16 \mathrm{~h}$ photoperiod, to initiate a clonal culture of each genotype, which could then be karyotyped and analysed for amplified esterase genes by FISH, immunoassay and restriction analysis. All clones were also reared for three generations at $10 \mathrm{~h}$ photoperiod to determine their life cycle category and hence suitability for further breeding work.

Although up to 70 per cent hatch was obtained in some crosses, egg mortality was a major problem and many crosses failed completely, or yielded only a few viable eggs. No reasons could be found to account for this differential mortality under closely controlled conditions. Variable and often high mortality is a long-standing problem in breeding studies with $M$. persicae (Blackman \& Takada, 1977), but it was hoped that this would be solved when it became possible to break diapause in the laboratory. Fairly reliable methods are now available for artificially hatching eggs of several aphid species (Puterka \& Slosser, 1986; Wipperfürth \& Mittler, 1986; Newton \& Dixon, 1987; Via, 1992), but none of the species involved is host-alternating; that is, their eggs are adapted to survive on dead herbaceous plants at soil level. In contrast, the eggs of $M$. persicae would normally be laid on peach twigs, and more experimental work is needed to find a reliable method for artificially hatching eggs of such hostalternating aphids.

\section{Esterase gene characterization, karyotyping and FISH}

E4 and FE4 genes can be distinguished on Southern blots by their different restriction fragments; $E 4$ has an $8 \mathrm{~kb}$ band with EcoRI, and 2.8 plus $2.2 \mathrm{~kb}$ bands with MspI, whereas FE4 has a $4 \mathrm{~kb}$ band with $E c o$ RI, and 2.8 plus $1.8 \mathrm{~kb}$ bands with MspI (Fig. 3a). Methods for preparing chromosomes of embryonic somatic cells and male meiosis I stages, and for FISH, have already been described (Blackman et al., 1995). In addition to the $8 \mathrm{~kb} \mathrm{E4}$ probe 

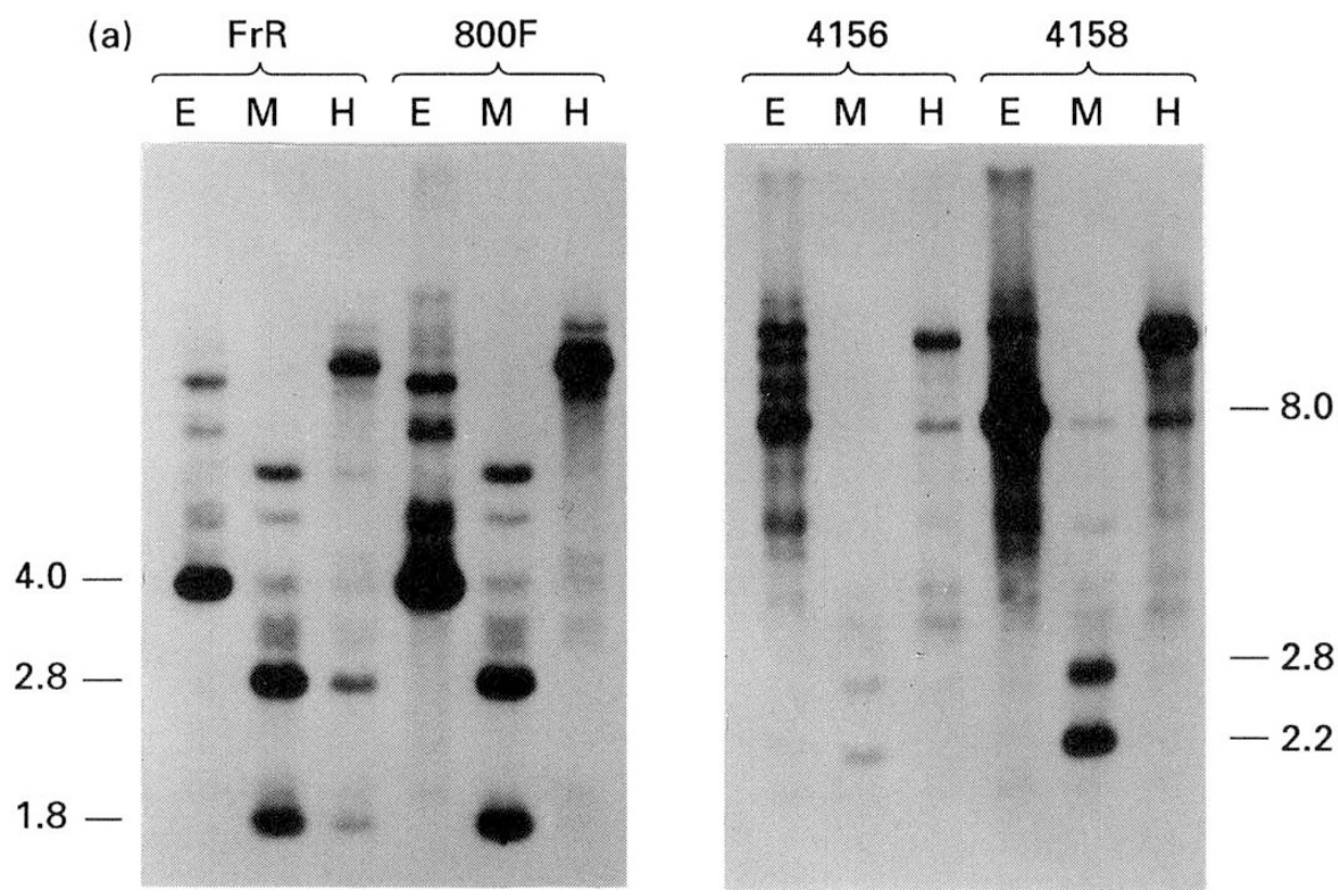

(b)
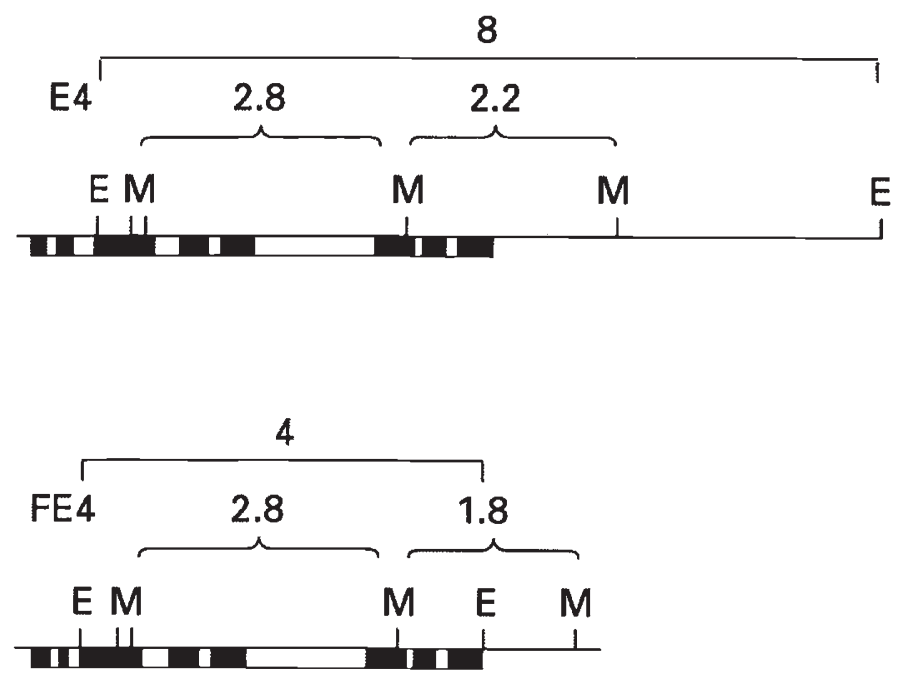

Fig. 3 (a) Autoradiographs of Southern blots showing binding of cloned esterase sequences to aphid genomic DNA digested with $E c o$ RI (E), MspI (M) and $H p a \mathrm{II}(\mathrm{H})$. French R and $800 \mathrm{~F}$ are parental clones with amplified $F E 4$ genes, 4156 and 4158 are parental clones with amplified $E 4$ genes; (b) restriction maps of amplified $E 4$ and $F E 4$ genes and $3^{\prime}$ flanking DNA, indicating the EcoRI (E) and $M s p \mathrm{I}(\mathrm{M})$ restriction sites, and the $8 \mathrm{~kb} E 4$ and $4 \mathrm{~kb} F E 4$ probes used for FISH.

used for FISH in previous work, we also used a $4 \mathrm{~kb}$ FE4 probe for preparations where it was important to maximize the signal from sites of amplified FE4 sequences. This probe was a cloned genomic DNA fragment extending from the EcoRI site in exon 3 to an EcoRI site just downstream of the gene (Field $e t$ al., 1993; and see Fig. 3b).

The presence of 5-methylcytosine $(5 \mathrm{mC})$ in the amplified esterase sequences was detected by differences between $M s p \mathrm{I}$ and $\mathrm{HpaII}$ restriction fragments 
(Field et al., 1989). Both enzymes have the same restriction site (CCGG), but only MspI cuts if the internal cytosine is methylated. Therefore, when the amplified esterase sequences are methylated, smaller fragments are seen in MspI digests but are absent in HpaII digests (e.g. 800F, 4156 and 4158 in Fig. 3a). When methylation is absent both enzymes give the same fragments, and if there is partial methylation, as in the FE4-producing parent clone French $\mathbf{R}$, HpaII digests show a combination of larger and smaller bands (Fig. 3a).

\section{Immunoassay}

The activity of E4 or FE4 was assayed for 12 individuals of each clone in microplates after trapping with a specific immunoglobulin $\mathrm{G}$ and removing other esterases by washing the plates with PBS/Tween (Devonshire et al., 1986). The absorbance in each well was measured at $620 \mathrm{~nm}$. Activities measured in this way (Table 1) reflect the molar amount of E4/FE4 esterase protein in an aphid (0.4-25 pmol $\mathrm{mg}^{-1}$ per aphid), as measured by titration with a radio-labelled site-directed ligand (Devonshire \& Sawicki, 1979).

\section{Results and discussion}

\section{Inheritance of FE4-based resistance from clone French $R$}

A cross between French $R$ (females) and DS (males) provided six $\mathrm{F}_{1}$ clones, of which four inherited the autosome 2 dissociation from the DS parent. FISH to somatic chromosomes of French $\mathrm{R}$ showed three sites of amplified FE4 esterase genes, all subtelomeric, with one appearing weaker than the other two (Blackman et al., 1995). These three sites appear to represent two loci, one homozygous and one heterozygous, in which case $F_{1}$ progeny would be expected to form two groups intermediate in resistance and esterase activity between the parent clones; indeed, two such groups were obtained in the $F_{1}$ of an earlier cross between French $\mathbf{R}$ and another susceptible parent clone (Blackman et al., 1977). Five of the six $\mathrm{F}_{1}$ clones of the present cross were intermediate in esterase activity between French R and DS but, because of the small number, it was impossible to discern any clear grouping, and the sixth clone appeared to be at least as resistant as French R (Fig. 4a,b).

Several attempts were made to self French $\mathbf{R}$, but none of the thousands of eggs laid was viable. Two French $\mathrm{R} \times \mathrm{DS} \quad \mathrm{F}_{1}$ clones were used for further breeding, $5 \mathrm{~N}$ and $6 \mathrm{D}$. FISH showed that $5 \mathrm{~N}$, with about half the esterase (FE4) activity of French R, had inherited two of the sites of amplified FE4 genes (Fig. 5a), whereas 6D had inherited only one (Fig. 5b), and had lower activity (Fig. 4). FISH applied to meiotic prophase I spermatocytes showed that the amplified site in $6 \mathrm{D}$ was on the undissociated homologue of autosome 2 inherited from French R (Fig. 5c). This indicates that the locus presumed to be homozygous for amplified FE4 sequences in French $\mathrm{R}$ is on autosome 2, and it follows from a comparison of chromosome lengths that the third, unpaired French $\mathrm{R}$ site is on autosome 1 .
Fig. 4 Logged mean esterase activities $\left(\mathrm{A}_{620}=\right.$ absorbance at $\left.620 \mathrm{~nm}\right)$ and karyotypes of parental, $\mathrm{F}_{1}$ and $\mathrm{F}_{2}$ Myzus persicae clones resulting from the French $\mathrm{R} \times \mathrm{DS}$ cross. Sib-mating of $\mathrm{F}_{1}$ clones $5 \mathrm{~N}$ and $6 \mathrm{D}$ produced an $\mathrm{F}_{2}$ generation with the expected segregation of three susceptible clones carrying the A2 dissociation (including 019D, used for further breeding work), and three karyotypically normal clones with the French $\mathrm{R}$ level of resistance. (a)

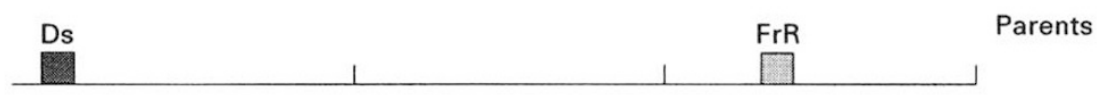

(b)

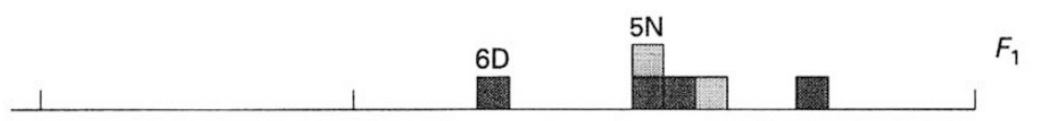

(c)

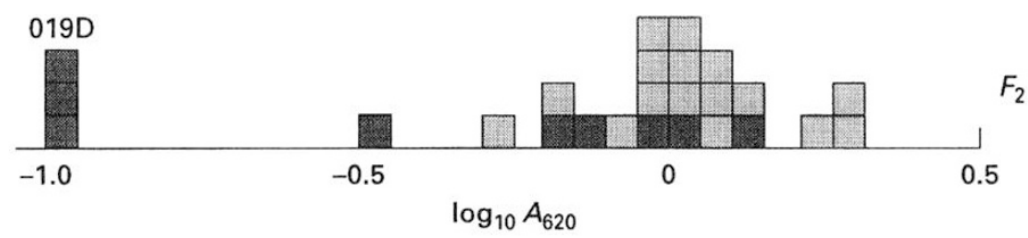



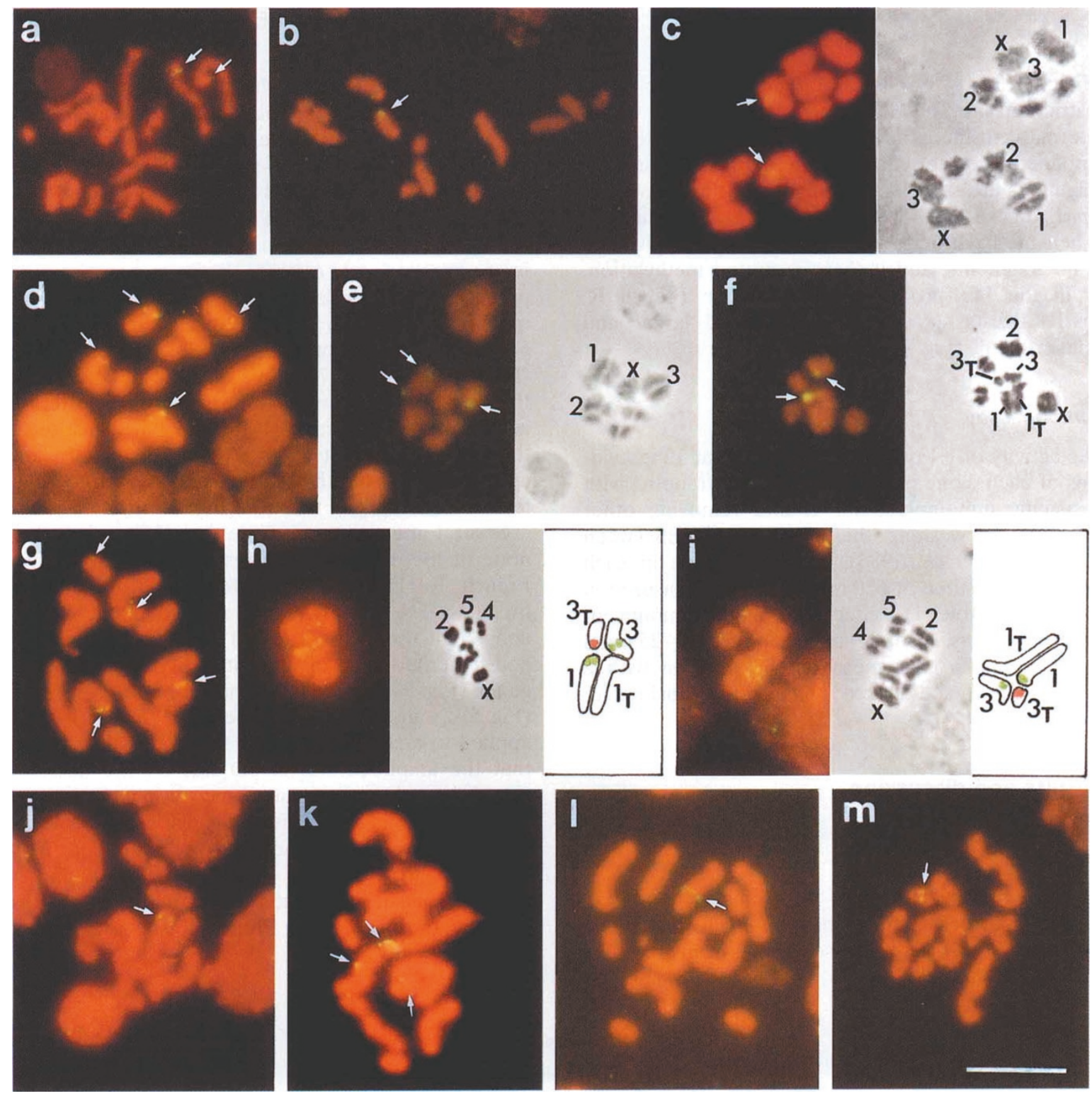

Fig. 5 In situ hybridization of esterase DNA probes to chromosomes of resistant clones of Myzus persicae obtained in inheritance studies, showing location of amplified $E 4$ and/or $F E 4$ sequences (arrowed): (a) clone $5 \mathrm{~N}$, somatic cell prometaphase, with sites of amplified FE4 sequence inherited from French R on autosomes 1 and 2; (b) clone 6D, somatic cell prometaphase, with a single site of amplified FE4 sequence on autosome 2; (c) clone 6D, two spermatocytes at metaphase I, compared (right) with the same cells photographed by phase contrast prior to FISH, identifying the location of the amplified FE4 gene on the undissociated homologue of autosome 2 inherited from French R; (d) clone 124N, somatic cell prometaphase, homozygous for amplified $F E 4$ genes on autosomes 1 and 2; (e) clone 24D, spermatocyte metaphase I, compared (right) with the same cell viewed by phase contrast, identifying the location of amplified $F E 4$ genes on autosomes 1 and 3 inherited from clone 800F; (f) clone 53T, spermatocyte metaphase I, compared (right) with the same cell viewed by phase contrast, showing the amplified FE4 site inherited from French $\mathrm{R}$ on the autosome 2 bivalent, and the $E 4$ site on autosome $3^{\mathrm{T}} ;(\mathrm{g})$ clone $108 \mathrm{~T}$, somatic prometaphase, showing two amplified $E 4$ sites from $4156\left(\right.$ on $3^{\mathrm{T}}$ and 5) and two amplified FE4 sites from $18 \mathrm{~N}$ (originally from $800 \mathrm{~F}$, on 1 and 3); (h) clone 108T, spermatocyte metaphase I hybridized to the $F E 4$ probe, compared (right) with the same cell viewed by phase contrast and a drawing of the quadrivalent identifying the amplified sites as E4 (red) and FE4 (green); (i) clone 108T, same as (h) only using the E4 probe, which hybridizes less strongly to the $F E 4$ sites; (j) clone $263 \mathrm{~N}$, with amplified $F E 4$ sequences only on autosome 1 ; (k) clone $103 \mathrm{~N}$, somatic prometaphase, showing amplified FE4 sites on autosomes 1 and 3 and the amplified $E 4$ site on 5 (FE4 probe, computer enhanced); (l) clone 269D, with amplified FE4 sequences only on autosome 3; (m) clone 271D, with amplified $E 4$ only on autosome 5 . Bar represents $10 \mu \mathrm{m}$. 
Sib-mating of $5 \mathrm{~N}$ females with $6 \mathrm{D}$ males yielded $25 \mathrm{~F}_{2}$ clones, 16 of normal karyotype and nine dissociated. Immunoassay showed that three of the clones with the dissociation had susceptible levels of esterase, and three karyotypically normal clones had similar esterase activity to the resistant parent French $\mathrm{R}$. The rest of the $5 \mathrm{~N} \times 6 \mathrm{D}$ clones had intermediate esterase activity (Fig. 4c). Although it was not possible to resolve the intermediate range into clones with either one or two amplified sites, the broad classification of esterase activities, and their association with karyotype, were fully in accordance with the two-locus model for French $\mathrm{R}$ (Table 2; $\chi_{3}^{2}=2.6$ ), corroborating an earlier study in which French $\mathrm{R}$ was crossed with a different susceptible

Table 2 Karyotypes and esterase types of Myzus persicae progeny from a cross between females from clone $5 \mathrm{~N}$ and males from clone $6 \mathrm{D}$

\begin{tabular}{llccc}
\hline Esterase & Karyotype & $\begin{array}{c}\text { Expected } \\
(\%)\end{array}$ & $\begin{array}{c}\text { Expected } \\
\text { (of 25) }\end{array}$ & $\begin{array}{c}\text { Observed } \\
\text { (of 25) }\end{array}$ \\
\hline FE4 & Normal & 50 & 12.5 & 16 \\
FE4 & Dissociated & 37.5 & 9.4 & 6 \\
S & Normal & 0 & 0 & 0 \\
S & Dissociated & 12.5 & 3.1 & 3 \\
\hline
\end{tabular}

clone (Blackman et al., 1977; Blackman \& Devonshire, 1978).

Selfing of $5 \mathrm{~N}$ yielded more than $100 \mathrm{~F}_{2}$ clones, with a broad spectrum of esterase activities ranging from susceptible to the level of French R (Fig. 6). Out of 100 clones tested, four were fully susceptible (expectation $=100 / 16=6.25$ ), but there were no other clearly defined groups, and activities were generally rather lower than expected. Eight clones were examined by FISH; two of these were susceptible and had no discernible signal, one had four amplified sites (clone $124 \mathrm{~N}$, apparently homozygous at two loci; Fig. 5d), one had three (as in French R), one had two, and three had only one amplified site (Fig. 6).

The French $\mathrm{R}$ parent showed only partial methylation of esterase sequences (Fig. 3b), and this trait was inherited by many of its progeny. Loss of methylation of $E 4$ sequences in $M$. persicae is correlated with loss of expression (Field et al., 1989), and could be the reason for the lower than expected immunoassay readings in many of the progeny from crosses involving French $\mathrm{R}$. The nature of this partial methylation is not clear; it could involve differences in methylation status between gene copies at one site, between sites, between cells or tissues, or between embryos within an individual aphid.
Fig. 6 Logged mean esterase activities of $100 \mathrm{~F}_{2}$ Myzus persicae clones obtained by selfing the French $\mathrm{R} \times \mathrm{DS}$ $F_{1}$ clone $5 N$. The arrows indicate the activities of five clones that were analysed by FISH, and the numbers above the arrows refer to the number of sites of amplified esterase genes in these clones.

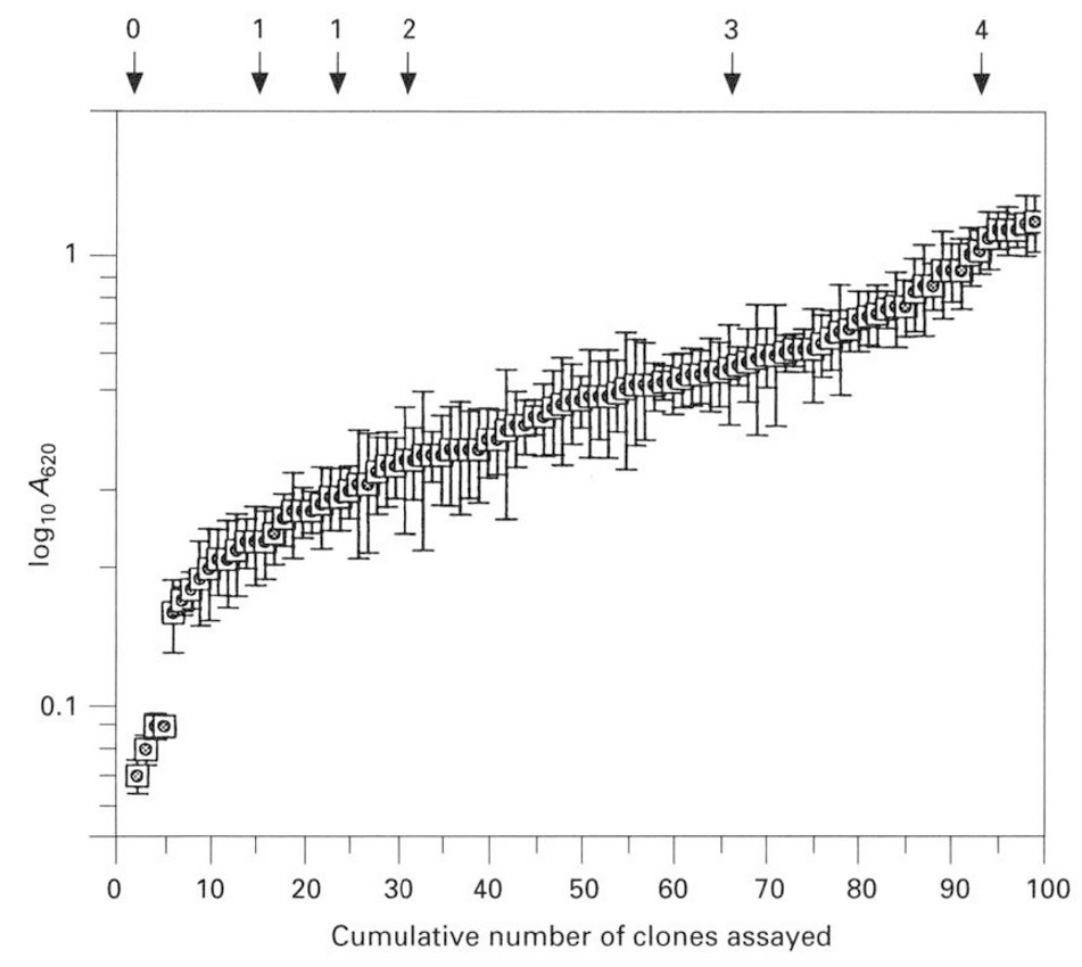




\section{Inheritance of FE4-based resistance from clone} $800 F$

A cross between $800 \mathrm{~F}$ (females) and DS (males) provided $33 \mathrm{~F}_{1}$ clones, of which 25 were karyotyped and 12 had inherited the autosome 2 dissociation from DS (expectation $=50$ per cent $=12.5$ ). FISH to somatic chromosomes of $800 \mathrm{~F}$ showed five sites of amplified esterase genes, and FISH to meiotic cells indicated that $800 \mathrm{~F}$ probably has two loci homozygous for amplified sequences on different chromosomes, and a third locus on one of these chromosomes heterozygous for amplified genes (Blackman et al., 1995). These loci could be assigned to particular chromosomes by examining meiotic cells of a particular $F_{1}$ clone (24D) that had inherited both the autosome 2 dissociation marker from DS and the amplified sequences at all three loci from $800 \mathrm{~F}$. None of these loci was on the undissociated autosome 2 (Fig. 5e), confirming that the resistance loci in $800 \mathrm{~F}$ must be on autosomes 1 and 3 .

In immunoassays, all $800 \mathrm{~F} \times \mathrm{DS} \mathrm{F}_{1}$ clones had elevated esterase (FE4) activity, ranging from 53 to 88 per cent of that of $800 \mathrm{~F}$. The absence of susceptible progeny confirmed that one or more loci were homozygous for amplified genes. A further indication of this homozygosity was obtained by selfing $800 \mathrm{~F}$, which provided $22 \mathrm{~F}_{1}$ clones with esterase activities similar (range $85-112$ per cent) to that of the parent clone.

Two $F_{1}$ clones from the $800 \mathrm{~F} \times \mathrm{DS}$ cross, $11 \mathrm{~N}$ and $18 \mathrm{~N}$, both with about 60 per cent of the esterase activity of $800 \mathrm{~F}$, were each selfed. They yielded four and $18 \mathrm{~F}_{2}$ clones, respectively, with esterase activities $13-81$ per cent that of $800 \mathrm{~F}$, but the clone with least activity still produced more than four times the esterase found in susceptible clones.

\section{Crosses between E4-producing and FE4-producing genotypes}

Males of the E4-producing, translocated clone 4158 were mated with females of clone $5 \mathrm{~N}$, one of the $\mathrm{F}_{1}$ progeny from French $\mathrm{R} \times \mathrm{DS}$, and heterozygous for amplified FE4 genes on autosomes 1 and 2 (Fig. 1b, and see above). Of the $31 \mathrm{~F}_{1}$ clones obtained, only three had the translocation (expectation $=50$ per cent). Two of these (053T and 066T) had inherited both E4 and FE4 genes, and the third (067T) had only E4. FISH to male meiotic chromosomes of clone 053T showed the amplified FE4 site on the autosome 2 bivalent, as well as the $E 4$ site on autosome $3^{\mathrm{T}}$ (Fig. 5f). The 28 karyotypically normal clones were in the expected proportions of 3 FE4-producing: 1 susceptible (Table 3 ).

When immunoassayed, the FE4-producing clones appeared to form two groups according to esterase activity, which might be expected to correspond with the inheritance of one or both amplified FE4 sites from $5 \mathrm{~N}$. This expectation was not fully realized when 11 of the FE4-producing clones were examined by FISH; one clone in the lower group of esterase activity had two amplified sites, and one in the upper group had a single site (Fig. 7). The esterase activities of all the FE4-producing clones with two amplified sites were low in comparison with the parent clone 5N (cf. Fig. 4).

This immunoassay was carried out on the third parthenogenetic generation, and the three translocated clones had esterase activities only 10-30 per cent that of the parent clone 4158. Most of the clones arising from this cross had previously been immunoassayed in the first parthenogenetic (= fundatrix) generation; the esterase activities of the two translocated clones assayed at that time,

Table 3 Karyotypes and esterase types of Myzus persicae progeny from a cross between females from clone $5 \mathrm{~N}$ (FE4-producing) and males from clone 4158 (E4-producing, translocated)

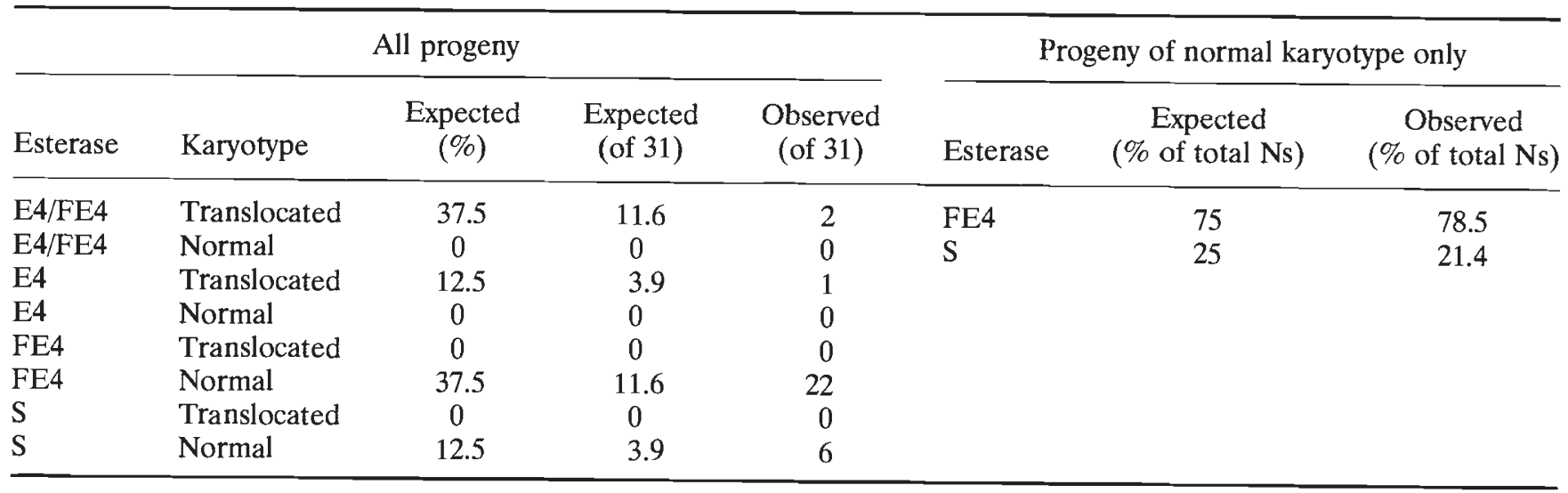


066T and 067T, were much higher (Fig. 8), indicating that the expression of the E4 locus in these clones is unstable, as frequently found in clones with translocation-linked resistance (Blackman \& Takada, 1977; ffrench-Constant et al., 1988).

Males from 4156, the translocated clone which untypically had three unlinked E4 loci (Blackman et al., 1995), were mated with females from $18 \mathrm{~N}$, one of the $F_{1}$ clones from $800 F \times D S$ (Fig. 1c). Unfortunately, $18 \mathrm{~N}$ was lost before the number and positions of its amplified FE4 sites could be established by FISH, but the range of esterase activities in clones produced by selfing $18 \mathrm{~N}$ suggested that it had inherited two unlinked amplified sites from 800F (on autosomes 1 and 3 ). The $18 \mathrm{~N} \times 4156$ cross yielded 12 clones, of which five had the translocation (Fig. 9). As expected, none of the translocated clones had $F E 4$ alone, because one amplified $E 4$ locus is linked to the translocation. Although the number of $18 \mathrm{~N} \times 4156$ clones was small, the range and combinations of karyotypes, esterase types and esterase activities was in close agreement with that expected for a cross between these parents $\left(\chi_{7}^{2}=5.23 ;\right.$ Table 4$)$.

The numbers and positions of the amplified sites in all $1218 \mathrm{~N} \times 4156$ clones were analysed by FISH and compared with their esterase activities determined by immunoassay (Fig. 9). The number of
Fig. 7 Logged mean esterase activities and karyotypes of Myzus persicae clones obtained by crossing females from $5 \mathrm{~N}$ (FE4-producing, normal karyotype) with males from 4158 (E4-producing, with A1,3 translocation). The immunoassay was performed on individuals of the third parthenogenetic generation. Numbers in squares indicate the numbers of sites of amplified esterase genes seen by FISH ("-' indicates not examined).
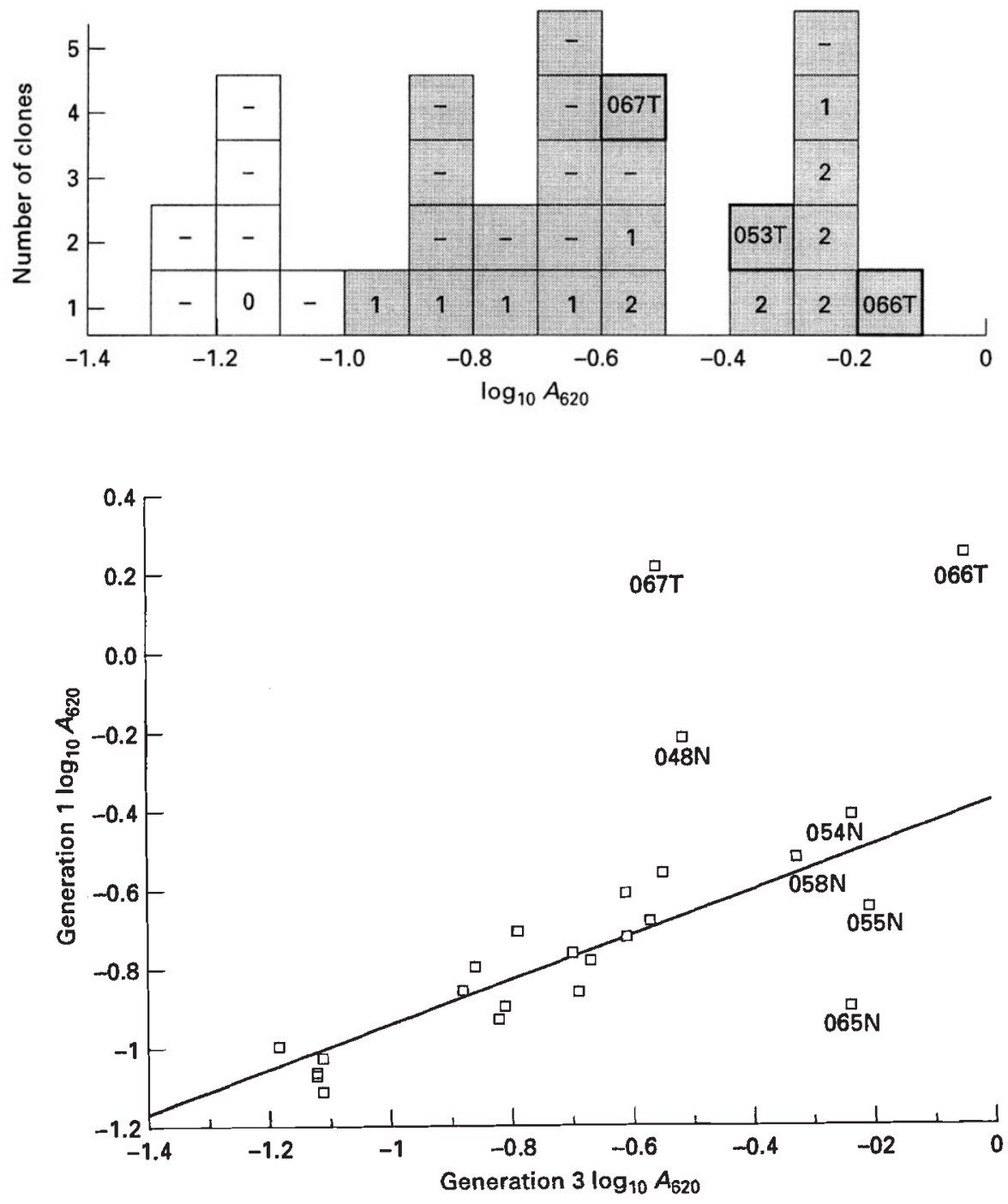

Fig. 8 Bivariate plot comparing esterase activities of fundatrices of clones of the $5 \mathrm{~N} \times 4158$ cross with the mean activities of 12 aphids from the same clones in the third parthenogenetic generation. Clones with the $\mathrm{A} 1,3$ translocation (066T, 067T), and five karyotypically normal clones which were revealed by FISH to have two sites of amplified esterase sequences, are individually identified.
Susceptible

Normal karyotype, resistant

Translocated, resistant

(C) The Genetical Society of Great Britain, Heredity, 77, 154-167. 


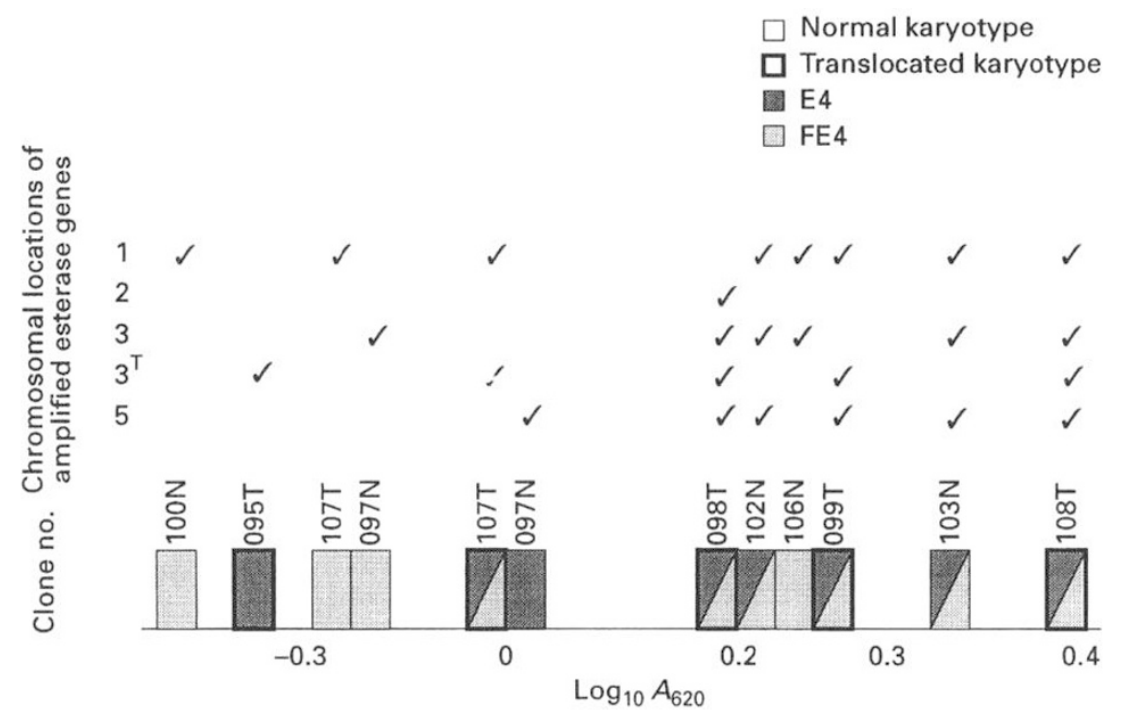

Fig. 9 Karyotypes, esterase activities and chromosomal locations of amplified esterase genes, of clones obtained by crossing females from clone $18 \mathrm{~N}$ (two amplified FE4-producing sites, normal karyotype) with males from clone 4156 (three amplified E4-producing sites and $\mathrm{A} 1,3$ translocation). Each tick represents a site of gene amplification, aligned vertically with the aphid clone and horizontally with chromosome number.
Table 4 Karyotypes and esterase types of Myzus persicae progeny from a cross between females of clone $18 \mathrm{~N}$ (FE4-producing) and males of 4156 (E4-producing)

\begin{tabular}{lcccc}
\hline Esterase & Karyotype & $\begin{array}{c}\text { Expected } \\
(\%)\end{array}$ & $\begin{array}{c}\text { Expected } \\
\text { (of 12) }\end{array}$ & $\begin{array}{c}\text { Observed } \\
\text { (of 12) }\end{array}$ \\
\hline E4/FE4 & T & 37.5 & 4.5 & 4 \\
E4/FE4 & $\mathrm{N}$ & 28.1 & 3.4 & 2 \\
E4 & $\mathrm{T}$ & 12.5 & 1.5 & 1 \\
E4 & $\mathrm{N}$ & 9.4 & 1.1 & 1 \\
FE4 & $\mathrm{T}$ & 0 & 0 & 0 \\
FE4 & $\mathrm{N}$ & 9.4 & 1.1 & 3 \\
S & $\mathrm{T}$ & 0 & 0 & 0 \\
S & $\mathrm{N}$ & 3.1 & 0.4 & 1 \\
\hline
\end{tabular}

amplified sites was highly correlated with esterase activity ( $r=0.85,10$ d.f., $P<0.001)$, but there also seemed to be some correspondence with the intensity of fluorescence at particular sites. The most strongly fluorescing site in clone 4156 is on autosome 5, and all the progeny with E4 in the upper range of esterase activity had this autosome 5 site, together with at least one FE4 site.

The clone with the highest esterase activity, 108T, had inherited two amplified $E 4$ sites from 4156 and two amplified FE4 sites from $18 \mathrm{~N}$ (Fig. $5 \mathrm{~g}$ ). The chromosomal locations of the four sites in this clone were verified using FISH applied to male meiotic chromosomes (Fig. 5h,i). This showed three amplified sites to be closely associated on the quadrivalent formed by normal and translocated homologues of autosomes 1 and 3 in prophase I. In particular, the $E 4$ site on $3^{\mathrm{T}}$ seemed to be paired with the FE4 site on the normal autosome 3, suggesting that they may be coallelic.

Selfing of clone $108 \mathrm{~T}$ yielded 11 clones, which were all translocated, compared with the expectation of 2:1 translocated:normal (as translocation homozygotes are inviable). The esterase activities of these 11 clones ranged from 70 to 124 per cent of that of 108T, depending on whether 0,1 or 2 amplified sites on autosome 5 had been inherited. All these clones had inherited the FE4 sites on autosomes 1 and 3 as well as the $E 4$ site on $3^{\mathrm{T}}$, indicating that no crossovers had occurred between these sites in female meiosis I (male meiosis I is achiasmate).

\section{Backcrosses to susceptible clone 019D}

Clone 019D, a granddaughter of the susceptible clone DS with the same autosome 2 dissociation (see Fig. 1a), was crossed with resistant clones having amplified genes at identified chromosomal locations. The aims were (1) to study further the degree of linkage between the A1,3 translocation and the amplified sites on autosomes 1,3 and $3^{\mathrm{T}}$, and (2) to breed genotypes with amplified genes at single sites. Unfortunately, only two of these crosses provided sufficient progeny for genetic analysis. These were $098 \mathrm{~T}$ (females) $\times 019 \mathrm{D}$ (males), and 019D (females) $\times 103 \mathrm{~N}$ (males); 098T and $103 \mathrm{~N}$ were clones with high esterase activity from the cross between 18N and 4156 (see Figs 1c, 9).

Eighteen progeny clones were obtained from $098 \mathrm{~T} \times 019 \mathrm{D}$, and all four possible karyotypes were represented, including three clones which had inherited both the A1,3 translocation and the $\mathrm{A} 2$ dissociation, a combination not yet encountered in nature. 
One clone could not be included in the analysis as it had a de novo chromosomal rearrangement of uncertain origin; work on this clone will be reported elsewhere.

Southern blotting of MspI-digested DNA from 098T had shown that it had RFLPs characteristic of both E4 and FE4 genes, and FISH showed that it

Table 5 Karyotypes and esterase types of Myzus persicae progeny from a cross between females of clone 098T (E4 and FE4-producing) and males of 019D (susceptible)

\begin{tabular}{llccc}
\hline Esterase & Karyotype & $\begin{array}{c}\text { Expected } \\
(\%)\end{array}$ & $\begin{array}{c}\text { Expected } \\
\text { (of 17) }\end{array}$ & $\begin{array}{c}\text { Observed } \\
\text { (of 17) }\end{array}$ \\
\hline E4/FE4 & T & 0 & 0 & 0 \\
E4/FE4 & DT & 0 & 0 & 0 \\
E4/FE4 & N & 18.8 & 3.2 & 3 \\
E4/FE4 & D & 18.8 & 3.2 & 2 \\
E4 & T & 25 & 4.25 & 6 \\
E4 & DT & 25 & 4.25 & 3 \\
E4 & N & 0 & 0 & 0 \\
E4 & D & 0 & 0 & 0 \\
F & T & 0 & 0 & 0 \\
F & DT & 0 & 0 & 0 \\
F & N & 6.25 & 1.1 & 1 \\
F & D & 6.25 & 1.1 & 2 \\
S & T & 0 & 0 & 0 \\
S & DT & 0 & 0 & 0 \\
S & N & 0 & 0 & 0 \\
S & D & 0 & 0 & 0 \\
\hline
\end{tabular}

had amplified sites on chromosomes $2,3^{\mathrm{T}}$ and 5 (presumably E4) inherited from 4156 , and a site on chromosome 3 (presumably FE4) inherited from $18 \mathrm{~N}$ (Fig. 9). The combinations of karyotype and esterase type obtained when females of 098T were crossed with males of 019D were fully in accordance with expectations (Table 5). A key result was that the $E 4$ site on $3^{\mathrm{T}}$ and the FE4 site on 3 behaved as would be predicted if they were coallelic, none of the translocated progeny inheriting FE4-producing genes.

Esterase activities of the $098 \mathrm{~T} \times 019 \mathrm{D}$ progeny ranged from 21 to 65 per cent of that of the resistant parent $098 \mathrm{~T}$ and appeared to be unrelated to the presence or absence of the translocation (Fig. 10). Fifteen $098 \mathrm{~T} \times$ 019D clones were examined by FISH; the number of sites with amplified $E 4$ and/or FE4 sequences was correlated with esterase activity $(r=0.53,13$ d.f., $P<0.05)$.

Eleven clones were obtained from the cross 019D (females) $\times 103 \mathrm{~N}$ (males), of which four had inherited the autosome 2 dissociation from the susceptible parent $($ expectation $=50$ per cent $=5.5)$. The resistant parent, $103 \mathrm{~N}$, was heterozygous at three loci, with amplifed $F E 4$ sequences on autosomes 1 and 3 and amplified $E 4$ sequences on autosome 5 (Fig. 5k). One of the progeny clones was susceptible (expectation $=1 / 8=1.4$ ), and others had inherited each of the three $103 \mathrm{~N}$ sites in isolation (Fig. 5 $\mathrm{j}, \mathrm{l}, \mathrm{m})$.
Fig. 10 Logged mean esterase activities with 95 per cent confidence limits for 17 Myzus persicae clones obtained by crossing females from clone 098T with males from clone 019D. Esterase activities of the parent clones determined at the same time as their progeny are also plotted. Solid and open squares represent clones with and without the A1,3 translocation, respectively. Ticks above the plot indicate chromosomal locations of amplified esterase genes in 15 clones examined by FISH.

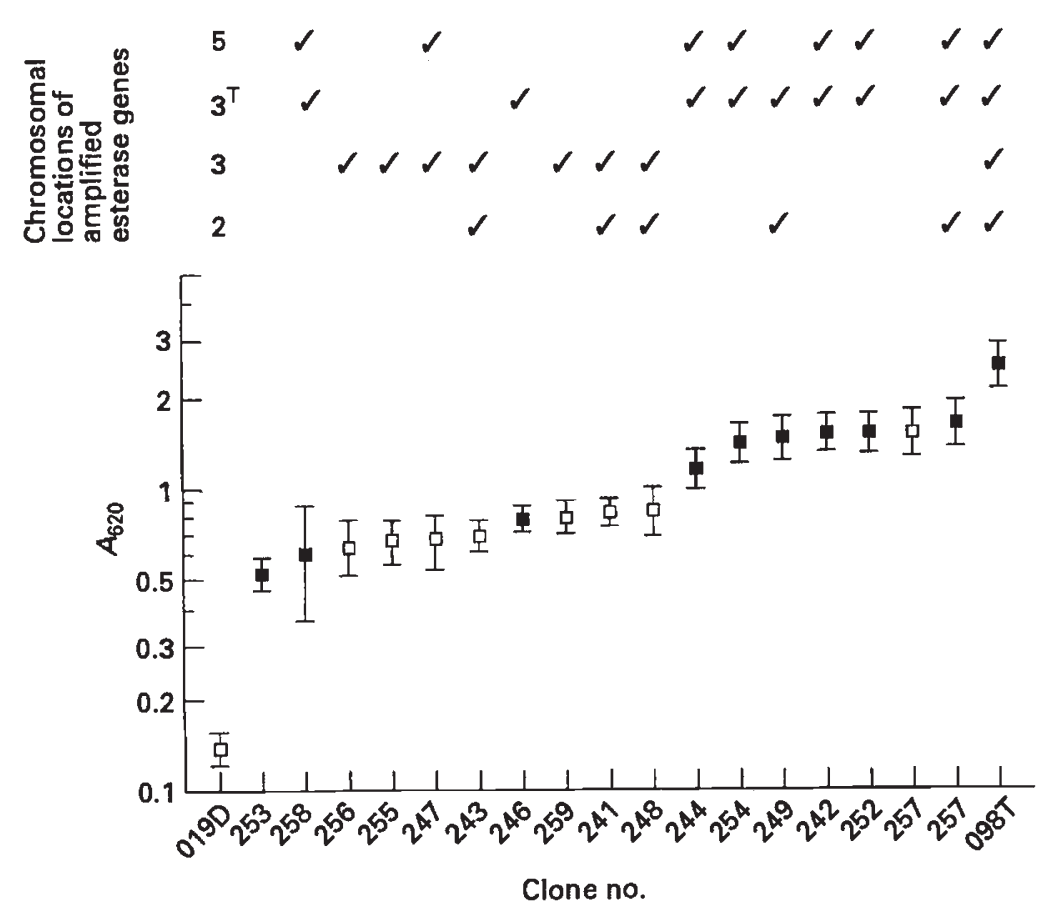




\section{Concluding remarks}

The proportions of translocated : normal progeny in two crosses deviated markedly from expectation. Males from clone 4158 crossed with females from clone $5 \mathrm{~N}$ passed their translocation to only three of 31 progeny instead of the expected 50 per cent. A recessive lethal on autosome 3 of $5 \mathrm{~N}$ and $3^{\mathrm{T}}$ of 4158 could only reduce the proportion of translocated progeny to 33 per cent, still significantly higher than the observed number $\left(\chi_{1}^{2}=7.8\right)$. A significantly lower proportion of translocated progeny than expected was also obtained in a previous cross between translocated males and normal females (Blackman et al., 1978); delayed hatching of aphids carrying the translocation was put forward as a possible explanation in that case, but cannot apply to the $5 \mathrm{~N} \times 4158$ cross because all progeny were kept, irrespective of hatching time.

In contrast, when clone $108 \mathrm{~T}$ was selfed all the 11 progeny clones were translocated, a deviation from the expected 2:1 translocated:normal with a probability of less than $0.05\left(\chi_{1}^{2}=5.5\right)$. In this case a recessive lethal on either autosome 1 or 3 of $108 \mathrm{~T}$ could explain the absence of karyotypically normal progeny. It is possible that recessive lethal mutations have accumulated in the parental aphid clones after many generations of apomixis.

Although the number of progeny obtained from the crosses was low, mainly because of high egg mortality, the success of FISH in locating the amplified esterase genes in parental clones and their progeny made this less of a problem. If the effects of karyotype-associated deviations are discounted, then within-karyotype inheritance of amplified esterase genes was fully in accordance with expectations.

The crosses confirmed the parental genotypes revealed by FISH, and provided progeny clones with single sites of amplified genes, so that each amplified site can now be studied in isolation. Immunoassay of these clones with single amplified sites showed that they all had elevated esterase activity, confirming that all the amplified E4 and FE4 sites revealed by FISH are actively expressed; i.e. none are pseudogenes.

E4- and FE4-amplified sequences can be combined in the same clones by crossing, yet have not been found together in nature. Possibly they are rare or absent because $E 4$ sequences are normally at a single site linked to the translocation, and translocated clones rarely contribute to the sexual phase on peach, so the opportunities for crossing in nature are limited (see Blackman et al., 1995, for further discussion). Another possibility is that clones with both E4 and FE4 are sometimes produced but become homogeneous for one or other of the two forms of amplified gene by some mechanism of molecular drive such as gene conversion (Dover, 1986).

The aphid clones generated now provide an invaluable resource for relating the structure, copy number and chromosomal location of the esterase genes to their function in the living organism. Work is in progress to obtain accurate data on copy number for each of the sites of amplification in the clones studied, as well as to investigate the full extent of variation in copy number and chromosomal location now present in resistant aphids in the field. In order to study the evolutionary processes involved in the development of resistance by gene amplification we are also attempting to locate and analyse the wild-type esterase genes in susceptible $M$. persicae and related species.

\section{Acknowledgements}

This work was supported by a Linked Research Groups grant from the British Biotechnology and Biological Sciences Research Council. We thank Jo Testa, Mary Stribley and Zoë Harburg for technical assistance, and Paul Ready for many useful discussions.

\section{References}

BLACKMAN, R. L. 1988. Rearing and handling aphids. In: Minks, A. K. \& Harrewijn, P. (eds) Aphids, their Biology, Natural Enemies and Control, vol. 2B, pp. 59-68. Elsevier, Amsterdam.

BLACKMAN, R. L. AND TAKADA, H. 1977. The inheritance of natural chromosomal polymorphisms in the aphid Myzus persicae (Sulzer). Genetica, 47, 9-15.

BLACKMAN, R. L., DEVONSHIRE, A. L. AND SAWICKI, R. M. 1977. Co-inheritance of increased carboxylesterase activity and resistance to organophosphorus insecticides in Myzus persicae (Sulzer). Pest. Sci., 8, 163-166.

BLACKMAN, R. L., SPENCE, J. M., FIELD, L. M. AND DEVONSHIRE, A. L. 1995. Chromosomal location of the amplified esterase genes conferring resistance to insecticides in the aphid Myzus persicae. Heredity, 74, 297-302.

DEVONSHIRE, A. L. AND FIELD, L. M. 1991. Gene amplification and insecticide resistance. Ann. Rev. Ent. , 36, 1-23.

DEVONSHIRE, A. L. AND SAWICKI, R. M. 1979. Insecticideresistant Myzus persicae as an example of evolution by gene duplication. Nature, 280, 140-141.

DEVONSHIRE, A. L., MOORES, G. D. AND FFRENCH-CONSTANT, R. H. 1986. Detection of insecticide resistance by immunological estimation of carboxylesterase activity in Myzus persicae (Sulzer) and cross reaction of the antiserum with Phorodon humuli (Schrank) (Hemiptera: 
Aphididae). Bull. ent. Res., 76, 97-107.

DOVER, G. A. 1986. Molecular drive in multigene families: how biological novelties arise, spread and are assimilated. Trends Genet., 2, 159-165.

FFRENCH-CONSTANT, R. H., DEVONSHIRE, A. L. AND WHITE, R. P. 1988. Spontaneous loss and reselection of resistance in extremely resistant Myzus persicae (Sulzer). Pestic. Biochem. Physiol., 30, 1-10.

FIELD, L. M., DEVONSHIRE, A. L. AND FORDE, B. G. 1988. Molecular evidence that insecticide resistance in peach-potato aphids (Myzus persicae Sulz.) results from amplification of an esterase gene. Biochem. J., 251, 309-312.

FIELD, L. M., DEVONSHIRE, A. L., FFRENCH-CONSTANT, R. H. AND FORDE, B. G. 1989. Changes in DNA methylation are associated with loss of insecticide resistance in the peach-potato aphid Myzus persicae (Sulz.). FEBS, 243, 323-327.
FIELD, L. M., WILLIAMSON, M. S., MOORES, G. D. AND DEVONSHIRE, A. L. 1993. Cloning and analysis of the esterase genes conferring insecticide resistance in the peachpotato aphid, Myzus persicae (Sulzer). Biochem. J., 294, 569-574.

NEWTON, C. AND DIXoN, F. G. 1987. Methods of hatching the eggs and rearing fundatrices of the English grain aphid, Sitobion avenae. Entomologia exp. appl., 45, 277-281.

PUTERKA, G. J. AND SLOSSER, J. E. 1986. Influence of host and temperature on greenbug, Schizaphis graminum (Rondani), egg hatch. Southwest. Entomol., 11, 75-81.

VIA, s. 1992. Inducing the sexual forms and hatching the eggs of pea aphids. Entomologia exp. appl., 65, 119-127.

WIPPERFÜRTH, T. AND MITTLER, T. E. 1986. A method for hatching eggs of the aphid Schizaphis graminum. Entomologia exp. appl., 42, 57-61. 